\title{
TRADUCCIÓN, GLOBALIZACIÓN Y TERRORISMO INTERNACIONAL: UNA LECTURA A TRAVÉS DE LA PRENSA ESPAÑOLA*
}

\section{Luis Pegenaute}

En esta comunicación pretendo estudiar cuál ha sido la representación que la prensa española ha hecho en los últimos años de la labor profesional de los traductores e intérpretes, con el fin de aventurar algunas hipótesis sobre el modo en que puede haber propiciado una mayor visibilidad social del colectivo y la construcción de una determinada imagen pública. Con el fin de llevar a cabo este estudio, me he ocupado de analizar las noticias en las que se presta atención de forma prominente a la traducción y a la interpretación y que han sido publicadas desde el año 2000 en un amplio acervo periodístico que comprende prensa nacional y autonómica, a la vez que semanarios. Evidentemente, estas noticias se ven mediatizadas por los distintos contextos de desarrollo cultural, tecnológico, político y económico de nuestra sociedad, pues vienen asociadas a la irrupción de rasgos prototípicos de nuestro tiempo. En ese sentido, apreciaremos que frecuentemente el tipo de labor desarrollada por los traductores e intérpretes al que se hace referencia en la prensa es consecuencia directa de fenómenos vinculados de algún modo al hecho de la globalización (mundialización, si queremos evitar el anglicismo propiciado por esa propia globalización).

Esta aportación se inscribe en la línea de investigación iniciada en los últimos años en los Estudios Descriptivos de Traducción, por lo que participa de los presupuestos planteados en lo que se ha dado en llamar "giro cultural", el cual se ha centrado en estudiar las relaciones que se pueden establecer entre poder y traducción a lo largo de la historia, dotando así a la disciplina de un amplio marco sociocultural que trasciende lo meramente textual. Más en concreto, se inscribe en dos líneas de investigación de muy reciente implantación: por una parte, en el estudio de la globalización en relación con la traducción a partir del desarrollo de los medios de comunicación en la llamada sociedad de la información, con particular atención a la incidencia que la traducción ha tenido en la preservación de la identidad cultural y

\footnotetext{
* Este trabajo se ha realizado en el marco del proyecto de investigación HUM2006-12972-C02-02 del Ministerio de Educación y Ciencia.
} 
lingüística (tal y como han hecho Schaffner 2000, Cronin 2003, Bielsa 2005, Bielsa \& Bassnett 2008); por otra parte, en el estudio del papel desarrollado por los traductores como agentes de intervención social en situaciones que requieren un posicionamiento ideológico o político y que han llevado a algunos autores (como Tymoczko 2000 o Baker 2006) a subrayar que la adopción de una determinada actitud de compromiso inhabilita la supuesta neutralidad de los traductores y a defender incluso, de manera sesgadamente prescriptiva, la conveniencia de adoptar un determinado comportamiento traductor, claramente intervencionista, que permita una mediación eficaz para lograr la restauración de un equilibro, en defensa de los principios de igualdad social. ${ }^{1}$ En relación con esta última línea de investigación, podríamos mencionar también los trabajos realizados por Apter (2006) o Salama Carr (2007a, 2007b), de corte más neutral, menos combativos políticamente en el postulado de pautas de comportamientos traductores deseables, y que se han ocupado igualmente de estudiar el papel desarrollado por los traductores en la resolución de conflictos bélicos. Por último, con el objetivo de acabar de ubicar metodológicamente este trabajo, quisiera recordar que, según Carol Maier (2007), cabe distinguir tres tipos de material documental en los que podemos rastrear la experiencia de los traductores desde el punto de vista de su papel como agentes de intervención, a saber: las representaciones ficticias en obras literarias, la escritura autobiográfica (desarrollada, evidentemente, por los propios traductores) y, finalmente, aquello que a nosotros nos compete -aunque sólo en parte- que no es sino el conjunto de representaciones no ficticias, en nuestro caso en particular, los reflejos en la prensa.

En un sentido amplio, la globalización ha consistido en la transformación de los fenómenos locales o regionales en fenómenos mundiales, lo que ha provocado una armonización de los comportamientos sociales a escala planetaria. La globalización, vista desde un punto de vista sociopolítico y económico, ha provocado un espectacular desarrollo en diversos campos: en la importación y exportación de bienes y servicios, en la inversión exterior, en el auge tecnológico y de las plataformas de la comunicación y también en los avances en los medios de transporte. Inevitablemente, la globalización ha tenido consecuencias colaterales negativas, que han determinado no sólo la pérdida de identidad cultural local sino también el desarrollo del terrorismo internacional y las migraciones masivas de individuos hacia países más favorecidos. Estos fenómenos han

\footnotetext{
${ }^{1}$ Véase Browlie (2007) para estudiar una crítica de estos modelos y la presentación de una alternativa, centrada en la filosofía de Derrida.
} 
hecho necesaria la constitución de grandes aparatos militares supranacionales y conjuntos coordinados de contrainteligencia, a la vez que la habilitación de servicios públicos de atención a los inmigrantes. Es en estos puntos de encuentro muchas veces traumático con el otro en los que centraré mi atención, vistos siempre desde la perspectiva de la intervención lingüística.

Desde una perspectiva lingüística, la globalización ha sido causa y efecto de dos elementos determinantes y, en apariencia, contradictorios: por una parte, la instauración del inglés como lingua franca; por otra, la necesidad cada vez más acuciante de salvar las barreras impuestas por la diversidad lingüística mediante la traducción y la interpretación. No valerse de estas herramientas para acceder a discursos que de otra forma resultarían opacos puede tener consecuencias calamitosas, incluso para la seguridad nacional.

Cabe señalar, tal y como ha hecho Chilton (1997), que en la consecución y resolución de los conflictos bélicos la traducción y la interpretación desarrollan un papel nada desdeñable. En primer lugar, la propia declaración de guerra ha de ser manifestada a la parte contraria en su propio código lingüístico, con el fin de que sea plenamente entendida; en segundo lugar, la maquinaria de guerra muchas veces sólo puede desplegarse gracias a la intervención de una intensa actividad verbal que pone en contacto a aliados que concursan en el acto bélico desde países en los que se hablan idiomas diferentes; en tercer lugar, la movilización de las tropas en terreno enemigo hace imperioso el establecimiento de comunicación con la población civil, con el fin de lograr su colaboración; en cuarto lugar, se hace necesario proceder a intensas labores de espionaje y contraespionaje; en quinto lugar, la negociación del armisticio hace necesario un intercambio dialéctico, que en ocasiones puede complicarse por la intervención de terceras partes (ya sean países en concreto u organizaciones supranacionales); finalmente, como consecuencia de la realización de actos terroristas o de crímenes de guerra que constituyen lesa humanidad se ha de proceder a la constitución de tribunales de justicia muchas veces multilingües.

Si pasamos ya a analizar las noticias de prensa, veremos que el atentado contra las Torres Gemelas de Nueva York demostró palpablemente que el FBI había cometido importantes fallos de contrainteligencia por no haber contado con suficientes traductores del árabe. En octubre de 2001 el diario El Periódico se hacía eco de cómo el director de la agencia, Robert Mueller, tras reconocer el problema, había abierto una convocatoria urgente para contratar traductores que entendieran el árabe, el farsi y el pashto (o 
afgano). También Michael Hayden, responsable de la Agencia de Seguridad Nacional (ASA), manifestó -en información recogida por El País en octubre de 2003- que su entidad había captado mensajes que podrían haber servido para alertar del inminente atentado si hubieran sido traducidos. La apertura de convocatorias para cubrir las plazas necesarias de traductores pasaba por una inspección exhaustiva sobre la trayectoria vital de los candidatos. Evidentemente, se pretendía así velar para que la traducción constituyera un ejercicio de fidelidad semántica y pragmática adecuado a los intereses estadounidenses, lo que, dicho de otro modo, es muestra palpable de la capacidad que podrían tener los traductores e intérpretes para subvertir el texto original, adaptándolo a la conveniencia de una de las partes, a saber, en este caso, las fuerzas terroristas.

De hecho, contamos con constataciones en la prensa de la labor subversiva o criminal desarrollada por algunos traductores. Así, en octubre del 2001 el diario El Periódico se hacía eco de la noticia aparecida en el diario Asaharq Al Ausat, en la que se aseguraba que Abdul-Aziz Musa al-Khamal, conocido por ser el intérprete que traducía al inglés las declaraciones del embajador talibán de Afganistán en Pakistán, había participado en el asesinato del presidente egipcio Anuar-al-Sadat y era un dirigente de la Jihad Islámica Egipcia, grupo terrorista vinculado a Bin Laden.

En abril del 2004, El País ofrecía un reportaje titulado “¿Un traductor traidor?” - llevando hasta sus últimas consecuencias el dicho italiano traduttore traditore que tanto ha pesado en la reputación de los traductores - y en el que informaba de que el ciudadano iraquí Al Mayali, contratado como traductor por el ejército español, había sido detenido para ser interrogado por los servicios de inteligencia españoles con el objetivo de esclarecer su participación en el atentado que había costado la vida a siete miembros del Centro Nacional de Inteligencia en noviembre de 2003. Al Mayali fue acusado de ser cooperador necesario en el atentado (por proporcionar datos a los terroristas sobre la ruta que iban a seguir los españoles) y se mantuvo detenido durante once meses en la cárcel de Abu Graig, un penal bajo responsabilidad de los Estados Unidos, pero fue puesto finalmente en libertad sin cargos. Cuatro días después de su liberación, en una entrevista publicada por La Vanguardia, Al Mayali acusó a sus interrogadores de haberle dado un trato inhumano, lo que hizo que Amnistía Internacional exigiera al Gobierno que se investigaran los abusos. Dos partidos políticos pidieron explicaciones en el Congreso. Años más tarde, en julio del 2007, tanto el diario El País como La Vanguardia volvieron a prestar atención al caso de Al Mayali. Según La Vanguardia, en una crónica titulada "Una investigación en el olvido", Al Mayali 
afirmaba que el Ministerio de Defensa español había aprovechado su detención para dejarle a deber unos 30.000 dólares de los 70.000 que habría obtenido como beneficios por una decena de contratos con el ejército español. En los reportajes publicados en ambos diarios manifestaba su deseo de comparecer ante la Audiencia Nacional para demostrar su inocencia, lo que no podía hacer por tener supuestamente prohibida la entrada en España. Hipotéticamente, su presencia en nuestro país iría en contra de los intereses del Centro Nacional de Inteligencia, que no deseaba volver a reabrir el sumario y desvelar las deficiencias cometidas en la investigación judicial.

Contamos también con la noticia de prensa publicada por La Vanguardia en enero de 2007, en la que se exponía que Daniel James, soldado británico de origen iraní que desarrollaba tareas de traducción en Afganistán a las órdenes del teniente general de las fuerzas internacionales de la OTAN, había sido acusado de pasar información secreta al gobierno de Irán. James, que contaba con importantes ingresos económicos como propietario de diversos bienes inmuebles en Inglaterra, se había alistado como voluntario en el Ejército Territorial inglés, una especie de Unidad de Reserva para responder a emergencias, y había aceptado la propuesta de ejercer como traductor en Afganistán por sus conocimientos del dari (dialecto del farsi) y del pashto. La integración de James en el ejército había tenido lugar en plena campaña de reclutamiento de espías, soldados y traductores con conocimientos de lenguas árabes.

El País también se hizo eco en 2004 de un informe presentado por el programa Marketplace de la cadena de radio pública estadounidense, según el cual los traductores que trabajaban en Irak con la coalición para la Autoridad Provisional o para las contratas se habían convertido en figuras muy corruptas. Al menos una docena de empresarios iraquíes entrevistados por Marketplace aseguraban haber recibido visitas de traductores que les prometían suculentas contratas a cambio de quedarse con el 50\% del trato.

En un sentido marcadamente diferente, La Vanguardia (octubre de 2007) documentaba cómo los intérpretes iraquíes que trabajaban para las fuerzas de ocupación eran considerados traidores y colaboracionistas por los insurgentes, que habían torturado y asesinado a cientos de ellos, lo que había forzado al gobierno británico a acabar aprobando un plan de asilo político para los intérpretes que hubieran trabajado más de un año para el ejército británico. El diario El Mundo, por su parte, rendía en setiembre de 2007 homenaje en un largo reportaje a Rooulah Masavi, el intérprete afgano fallecido en el atentado que también había costado la vida a dos paracaidistas 
españoles. En el artículo se constataban las abismales diferencias retributivas de que eran objeto los intérpretes contratados en el propio Afganistán y aquellos desplazados desde España, iraníes con pasaporte español. No era la primera vez que fallecía un intérprete al servicio de tropas españolas: el bosnio Mirko Mikulcic había muerto en Mostar en 1994 al volcar el blindado en que viajaba.

En cualquier caso, retomemos el hilo del discurso antes iniciado. En sintonía con la noticia aludida sobre la falta de traductores en Estados Unidos, El País informaba en mayo de 2003 de que los departamentos de recursos humanos de los servicios secretos occidentales habían comenzado a abrir convocatorias públicas de contratación, haciendo uso incluso de Internet para su difusión. Tal era el caso del Centro Nacional de Inteligencia español, en su oferta de plazas de traductor (en particular de ruso, georgiano, alemán, chino, urdu, farsi y árabe). Lamentablemente, la situación de déficit en materia de traductores de estas lenguas no fue tempranamente solventada, lo que hizo que en España hubiéramos de reconocer poco tiempo más tarde problemas de contrainteligencia similares a los norteamericanos cuando sufrimos nuestro 11-S particular, el 11-M. El País informaba en mayo de 2004 de que la policía había pinchado el teléfono del terrorista Zougam, uno de los supuestos autores materiales de los atentados del 11-M, pero no pudo traducir el contenido de las conversaciones, ya que las cintas, grabadas hasta nueve meses antes de la masacre, se habían acumulado por falta de traductores del dialecto árabe usado por el sospechoso. Tras la detención de Zougam se recuperaron las cintas grabadas y fueron traducidas, pero no se pudieron encontrar referencias a los atentados, a pesar de que, según se ha podido comprobar posteriormente, Zougam tuvo una importante participación.

Felizmente, La Vanguardia pudo anunciar en noviembre de 2004 que el Ministerio del Interior acababa de crear 99 plazas de traductores "para atender las necesidades que plantean las investigaciones sobre terrorismo islamista". La carencia de traductores habría sido ya puesta de manifiesto por las autoridades policiales con anterioridad a los atentados del 11-S del 2001 y se habría hecho evidente tras el 11-M. En el Ministerio del Interior se subrayaba la dificultad de contratar a este tipo de especialistas, dado que ejercían una labor que afectaba a la seguridad del estado. Ese mismo mes de noviembre de 2004 El País informó de que, antes de la fecha de la catástrofe española, ese ministerio destruía las grabaciones a terroristas islamistas por carecer de traductor. La política antiterrorista del Gobierno habría sufrido así una fuga de información relevante por la falta de traductores de árabe asignados a la Dirección 
General de Instituciones Penitenciarias. Todas las comunicaciones de presos islamistas acusados de delitos de terrorismo fueron grabadas, en aplicación de la ley, pero nadie las transcribió porque no existían traductores de árabe. Instituciones Penitenciarias carecía de un intérprete de árabe a pesar de que, desde 1997, habían comenzado las encarcelaciones de presos sospechosos de actividades terroristas relacionadas con el fundamentalismo islámico. Si bien todo el material relacionado con la intervención de las comunicaciones a presos relacionados con bandas armadas - fundamentalmente cartas y cintas magnetofónicas con la grabación de sus conversaciones- se enviaba desde las cárceles al Servicio de Coordinación de Seguridad, ante la imposibilidad de traducir el material al árabe, dicho servicio repartía las cartas entre los departamentos policiales que habían investigado las actividades de los terroristas en cuestión, pero devolvía las cintas a las cárceles para su reutilización (con la consiguiente destrucción de las grabaciones originales), tras haber permanecido custodiadas durante dos meses en Instituciones Penitenciarias a disposición de las fuerzas antiterroristas.

La celebración del juicio del 11-M supuso un exigente ejercicio de traducción, no sólo por la trascendencia de los actos que se juzgaban y la presión mediática, sino también porque comportaba grandes dificultades técnicas (escucha de material grabado en condiciones nefastas y hasta problemas con los sistemas de interpretación, que les valieron una reprimenda por parte del juez, tal y como recogió la prensa), y también lingüísticas (uso de diferentes dialectos árabes). En alguna ocasión los intérpretes se convirtieron en protagonista absoluto de la investigación, convirtiendo auténticos debates sobre la fidelidad deseable en el cumplimiento del ejercicio interpretativo o sobre la supuesta falta de profesionalidad de determinados intérpretes en materia sustancial para la comprobación veraz de los hechos que se juzgaban. Así, el diario El mundo, en mayo de 2007, se hacía eco de cómo los intérpretes del juicio del 11-M pusieron en duda la principal prueba contra Rabei Osman el Sabed, 'Mohamed el Egipcio', que eran unas conversaciones grabadas por la Policía italiana en su piso de Milán. Según la transcripción hecha por los italianos, Rabei se atribuía el proyecto de los atentados y se situaba a sí mismo en un entorno de mártires, yihadistas y Al Qaeda. Para los intérpretes españoles, sin embargo, la transcripción de las 60 horas de grabaciones estaba plagada de interpretaciones incorrectas y mostraba un alarmante desconocimiento de referencias históricas y relativas al Corán. Además, se achacó a los traductores italianos cierta "ligereza" y "poca responsabilidad" al hacer sus transcripciones por haber intentado proporcionar un contexto que no existía. "Se dicen 
cosas que no están. Muchas cosas no las hemos oído y otras creemos que son malas interpretaciones por desconocimiento". Estas manifestaciones de los intérpretes españoles, que causaron evidentemente gran desazón a la fiscal, propiciaron que el tribunal aceptara la comparecencia de los intérpretes italianos en el juicio, con el fin de realizar una prueba pericial. Si algo resulta interesante de esta rocambolesca situación es el hecho de que fueron los mismos intérpretes que traducían en el juicio oral para que los acusados comprendieran la marcha del proceso y se hicieran también comprender aunque, según los propios intérpretes, eran vistos por tales acusados como colaboradores en contra de su causa- los que actuaron como peritos a instancias de su abogado defensor. De igual modo, fue otro equipo de intérpretes -el italiano- el que actuó en beneficio de la posición mantenida por la fiscalía. Como consecuencia de este conflicto de intereses, el devenir del juicio vino dado en buena medida por un debate traductológico, trasladado a la propia sala de la Audiencia Nacional. En este contexto no es de extrañar que la presidenta de la Asociación Profesional de Traductores e Intérpretes Judiciales publicara en El País una carta en la que señalaba: "Se ha puesto de manifiesto la importancia que puede tener la interpretación de una sola palabra, que puede convertir a un hombre en ideólogo de una matanza o en mero conocedor previo de la misma”. Desde esta asociación se aprovechaba para criticar la falta de personal propio del Ministerio de Justicia bien cualificado y el hecho de haber tenido que recurrir al Ministerio de Exteriores para la coordinación del grupo de intérpretes que había actuado en el juicio.

A modo de conclusión, podemos sugerir que la ingente cobertura periodística de los grandes atentados del 11-S y 11-M ha servido, de forma indirecta, para llamar la atención sobre el papel destacado que cumplen los traductores y los intérpretes en la resolución de conflictos y también de su capacidad para evitarlos. De igual modo, se ponen de manifiesto las dificultades de su cometido y la posibilidad de un posicionamiento partidista que impide alcanzar la neutralidad con que muchas veces se les asocia. Es importante destacar en este contexto el interés que en los últimos años ha despertado en los Estudios de Traducción la figura del traductor como agente de intervención social en contextos geopolíticos. Conforme la globalización y los conflictos bélicos superan las fronteras lingüísticas, culturales y nacionales, resulta sintomático el desarrollo cada vez más frecuente de estudios sobre sociología de la traducción y la atención a los aspectos éticos de su actividad. En ese sentido, es necesario mencionar la participación cada vez más frecuente de traductores e intérpretes 
en movimientos activistas que desarrollan iniciativas altamente comprometidas en el ámbito político y social, aunque lamentablemente no hemos tenido espacio para referirnos a ellas. Sería deseable contar, por otra parte, con un mayor acervo biográfico y testimonial de los traductores e intérpretes que nos permitiera estudiar no sólo sus hábitos de comportamiento, sus diferentes respuestas ante los retos y exigencias planteados por los distintos encargos de traducción sino también el modo en que imbrican esa actividad con su existencia vital como ciudadanos del mundo.

\section{Bibliografía:}

APTER, Emily (2006) "Translation after 9/11: mistranslating the art of war". The translation zone: a new comparative literature, 12-22. Princeton / Oxford: Princeton University Press.

BAKER, Mona (2006) Translation and conflict: a narrative account. London: Routledge.

BIELSA, Esperança (2005) "Globalisation and translation: a theoretical approach". Language and Intercultural Communication 5 (2), 131-144.

\& BASSNETT, Susan (2008) Translation in the global news. London: Routledge.

BROWNLIE, Siobhan (2007) "Situating discourse on translation and conflict". Myriam Salama Carr (org.) Translation and Conflict (Social Semiotics 17: 2), 135-150.

CHILTON, Paul (1997) "The role of language in human conflict: prolegomena to the investigation of language as a factor in conflict causation and resolution". Current Issues in Language \& Society 4 (3), 174-189.

CRONIN, Michael (2003) Translation and globalization. London / New York: Routledge.

MAIER, Carol (2007) "The translator as an intervenient being”. Jeremy Munday (org.) Translation as intervention. London / New York: Continuum.

SALAMA CARR, Myriam (org.) (2007) Translating and interpreting conflict. Amsterdam / New York: Rodopi. (org.) (2007) Translation and Conflict (Social Semiotics 17 (2)).

SCHAFNER, Christina (org.) (2000) Translation in the global village. Clevedon (etc.): Multilingual Matters.

TYMOCZKO, Maria (2000) "Translation and political engagement: activism, social change and the role of translation in geopolitical shifts". The Translator 6 (1), 23-47. 